\title{
Characterization of forest fire smoke event near Washington, DC in summer 2013 with multi-wavelength lidar
}

\author{
I. Veselovskii ${ }^{1}$, D. N Whiteman ${ }^{2}$, M. Korenskiy ${ }^{1}$, A. Suvorina ${ }^{1}$, A. Kolgotin ${ }^{1}$, A. Lyapustin ${ }^{2}$, Y. Wang ${ }^{3}$, M. Chin ${ }^{2}$, \\ H. Bian ${ }^{4}$, T. L. Kucsera ${ }^{2,3}$, D. Pérez-Ramírez ${ }^{2,3}$, and B. Holben ${ }^{2}$ \\ ${ }^{1}$ Physics Instrumentation Center of General Physics Institute, Troitsk, Moscow, Russia \\ ${ }^{2}$ NASA Goddard Space Flight Center, Greenbelt, MD, USA \\ ${ }^{3}$ Universities Space Research Association, Columbia, MD, USA \\ ${ }^{4}$ Joint Center for Environmental Technology UMBC, Baltimore, MD, USA
}

Correspondence to: I. Veselovskii (igorv@pic.troitsk.ru)

Received: 16 September 2014 - Published in Atmos. Chem. Phys. Discuss.: 27 October 2014

Revised: 7 January 2015 - Accepted: 14 January 2015 - Published: 17 February 2015

\begin{abstract}
The multi-wavelength lidar technique was applied to the study of a smoke event near Washington, DC on 2628 August 2013. Satellite observations combined with transport model predictions imply that the smoke plume originated mainly from Wyoming/Idaho forest fires and its transportation to Washington, DC took approximately 5 days. The NASA Goddard Space Flight Center (GSFC) multiwavelength Mie-Raman lidar was used to measure the smoke particle intensive parameters such as extinction and backscatter Ångström exponents together with lidar ratios at 355 and $532 \mathrm{~nm}$ wavelengths. For interpretation of the observed vertical profiles of the backscatter Ångström exponents $\gamma_{\beta}$ at 355-532 and 532-1064 nm, numerical simulation was performed. The results indicate that, for fine-mode dominant aerosols, the Ångström exponents $\gamma_{\beta}(355-532)$ and $\gamma_{\beta}(532-$ 1064) have essentially different dependence on the particle size and refractive index. Inversion of $3 \beta+2 \alpha$ lidar observations on 27-28 August provided vertical variation of the particle volume, effective radius and the real part of the refractive index through the planetary boundary layer (PBL) and the smoke layer. The particle effective radius decreased with height from approximately $0.27 \mu \mathrm{m}$ inside the PBL to $0.15 \mu \mathrm{m}$ in the smoke layer, which was situated above the PBL. Simultaneously the real part of the refractive index in the smoke layer increased to $m_{\mathrm{R}} \approx 1.5$. The retrievals demonstrate also that the fine mode is predominant in the particle size distribution, and that the decrease of the effective radius with height is due to a shift of the fine mode toward smaller radii.
\end{abstract}

\section{Introduction}

Biomass burning (BB) is one of the key sources of aerosol emission. During large forest fires particles can be injected into the upper troposphere and transported over long distances affecting air quality in the subsidence regions. The processes of smoke particle production and transport on local and regional scales have been much studied over the last decade (Reid et al., 2005a, b; Adler et al., 2011; Pratt et al., 2011; Miller et al., 2011). Optical properties of the smoke particles near the source region may vary over a wide range depending on vegetation type, atmospheric conditions and combustion phase (see, for example, Reid et al., 2005a, b). The particles are modified during transport (so-called "smoke aging") due to different mechanisms, including hygroscopic water uptake (Hobbs et al., 1997), and coagulation (Fiebig et al., 2003), and are mixed with local anthropogenic emissions. To characterize the smoke particle properties, different kinds of observational techniques - such as satellite imaging (Miller et al., 2011), in situ aircraft probes (Fiebig et al., 2002, 2003) sun photometry (Dubovik et al., 2002; O'Neill et al., 2002) and star photometry (Pérez-Ramírez et al., 2008) - have been used. However, the general problem of passive sensors is that the results are appropriate for the particle column properties; thus the separate contributions of smoke layers, which may be above the planetary boundary layer (PBL), and aerosols within the PBL cannot be separated in a straightforward way. Aircraft sampling can be used to probe isolated aerosol layers but is too expensive to be done 
regularly. Meanwhile, active sensors, such as lidars, have the ability to profile the vertical structure of smoke plumes on a regular basis.

Previous multi-wavelength lidar measurements performed within the European lidar network (EARLINET), as well as measurements at other stations, have provided important information about intensive smoke particle parameters, such as lidar ratio and Ångström exponent (e.g., Müller et al., 2005, 2007a, b; Ansmann et al., 2009; Tesche et al., 2009; Amiridis et al., 2009; Murayama et al., 2004; Nicolae et al., 2013; Giannaki et al., 2010; Burton et al., 2012). In particular, analysis of parameters obtained for relatively fresh and aged smoke demonstrates a general trend of increasing lidar ratio as the particle ages. Thus lidar ratios at $355 \mathrm{~nm}\left(\mathrm{LR}_{355}\right)$ for smoke after 8 and 16 days, respectively, were about 45 and $80 \mathrm{sr}$ (Amiridis et al., 2009). The aging process leads also to a decrease of the Ångström exponent from approximately 1.8 (for 1-day-old smoke) to almost 0 for 20-day-old smoke (Müller et al., 2007a), which points to an increase of the particle size. Another interesting finding is that for aged smoke the lidar ratio at $532 \mathrm{~nm}$ generally exceeds $\mathrm{LR}_{355}$ (Müller et al., 2005, 2007a; Nicolae et al., 2013).

Moreover, measurements of aerosol backscattering and extinction at multiple wavelengths can be inverted to particle microphysical properties, e.g., effective radius, volume density and the complex refractive index (CRI) (Ansmann and Müller, 2005). Though multi-wavelength Raman lidar normally provides only five independent observations (three backscattering and two extinction coefficients), which is insufficient to obtain a unique solution, the use of reasonable constraints in the inversions permits a reasonable estimate of the particle characteristics to be made. Numerous approaches have been suggested for such inversion, with promising results being obtained (Müller et al., 1999; Böckmann et al., 2005; Veselovskii et al., 2002, 2012, 2013). Multi-wavelength Raman lidar retrievals of BB aerosol have already been presented by several groups for smoke of tropical, North American and Russian origin (e.g., Müller et al., 2005, 2007a; Ansmann et al., 2009; Tesche et al., 2009; Amiridis et al., 2011; Murayama et al., 2004; Baars et al., 2012; Nicolae et al., 2013). These measurements have shown that the characteristics of aged smoke particles and their vertical distribution are highly variable, even when particles of the same origin are considered. Thus additional independent measurements are desirable, particularly in North America, where multi-wavelength inversions of aerosol properties are fairly rare.

The earlier studies have focused on the long-range transport of Canadian forest-fire-generated aerosol and air quality impact on the east coast of the USA (Colarco et al., 2004; Miller et al., 2011). The current study considers the impact of forest wildfires in the western USA in August of 2013 as detected on the east coast of the USA by multi-wavelength Raman lidar at NASA Goddard Space Flight Center (GSFC). This paper focuses on the retrieval methodology providing vertical profiles of particle microphysical parameters from lidar measurements. The second (coming) part of this study, briefly summarized in the next section, should give a complex event characterization combining analysis of aerosol retrievals from MODIS with aerosol source attribution from back trajectories and the Goddard Chemistry, Aerosol, Radiation and Transport module in a global Earth system model framework (GEOS-5 GOCART) (Bian et al., 2013; Chin et al., 2002, 2014; Colarco et al., 2010).

\section{Results of lidar measurements}

\subsection{Lidar system overview}

Instrument: the measurements were performed with the multi-wavelength Mie-Raman lidar at NASA GSFC. The lidar is based on a Continuum 9050 laser with a $50 \mathrm{~Hz}$ repetition rate. The output powers at $\lambda=355,532$ and $1064 \mathrm{~nm}$ are 12,5 and $10 \mathrm{~W}$, respectively. The receiving SchmidtCassegrain telescope of $40 \mathrm{~cm}$ aperture was operated vertically, and the full geometrical overlap of the laser beam and the telescope field of view (FOV) is achieved at approximately $1000 \mathrm{~m}$ height. The system is capable of providing the so-called " $3 \beta+2 \alpha$ " optical data set: three backscattering coefficients at the laser wavelength and two extinctions calculated from nitrogen Raman signals at $\lambda_{R}=387$ and $608 \mathrm{~nm}$. Licel transient recorders allowed digitizing the outputs of the detectors both in analog and photon-counting mode at $7.5 \mathrm{~m}$ range resolution. For each profile, 6000 laser pulses were accumulated, so the temporal resolution of the measurements was 2 min. Backscattering and extinction coefficients at 355 and $532 \mathrm{~nm}$ were calculated from elastic and Raman backscatters (Ansmann et al., 1992). The reference point, where particles scattering can be neglected, was found for every individual profile. The backscattering coefficient at $1064 \mathrm{~nm}$ was obtained from backscatter, and extinction at $532 \mathrm{~nm}$ extrapolated to $1064 \mathrm{~nm}$, as described in Veselovskii et al. (2009).

Microphysical retrievals: the backscattering and extinction coefficients measured at several wavelengths were inverted to particle physical properties using the regularization (Müller et al., 1999; Veselovskii et al., 2002) and linear estimation (LE) approaches (Veselovskii et al., 2012; De Graaf et al., 2013). The inverse problem is strongly underdetermined. Therefore, successful inversions require a reasonable set of constraints which act as a priori assumptions in the retrieval. Specifically, we limit the range of the parameter values (the search space) that will be considered in the inversion. Specifically, we consider a set of predefined inversion windows determined by minimum $\left(r_{\min }\right)$ and maximum $\left(r_{\max }\right)$ values of radius and an increment interval. Similarly, we consider a set of predefined values of the CRI. A detailed description of the approach as applied to the regularization 
and linear estimation techniques has been published previously (Veselovskii et al., 2002, 2009, 2012).

A comparison of the regularization and LE demonstrates that these techniques generally have similar retrieval uncertainties, but that the LE technique is significantly faster (Veselovskii et al., 2013) due to the fact that with the LE technique we do not attempt to estimate the particle size distribution. Due to the speed advantage of the LE approach for evaluating bulk particle parameters, for the analysis done here, the vertical profiles of these parameters as well as their spatiotemporal variation were evaluated using the LE approach. The regularization technique was used to estimate the main features of the particle size distribution inside certain representative height intervals. The particle effective radius and volume density can be estimated with uncertainties not exceeding $25 \%$, while the uncertainty of the real part of the CRI estimation is typically \pm 0.05 (Veselovskii et al., 2002, 2012, 2013; Pérez-Ramírez et al., 2013). The imaginary part of CRI is the most difficult to retrieve as it depends strongly on the permitted range of $m_{\mathrm{I}}$ values. The smoke plume observed here was aged when measured, so the range of $m_{\mathrm{I}}$ values considered was restricted to the interval $0.001<m_{\mathrm{I}}<0.015$ (Nicolae et al., 2013).

\subsection{Meteorological analysis of event}

The lidar measurements at GSFC presented here were performed on 26-28 August 2013. On 26-27 August, observations were performed mainly during the daytime from 13:40 to 01:40 UTC. Further observations were prevented by clouds. High background noise in the $608 \mathrm{~nm}$ Raman $\mathrm{N}_{2}$ channel prevented the calculation of aerosol extinction coefficients from these data during the daytime. On 27 August daytime measurements were also restricted due to clouds, and thus only a short session of measurements occurred from 13:00 to 16:40 UTC. After sunset on 27 August, however, additional measurements were performed from 21:40 until 05:20 UTC on 28 August. For these nighttime measurements, the full $3 \beta+2 \alpha$ data set was available.

Figure 1 shows height-time distributions of backscattering coefficients at $355 \mathrm{~nm}$ during 26-28 August 2013. The data reveal the distinct aerosol layer at $3-5 \mathrm{~km}$ altitude which gradually subsides during 26 August and completely mixes with the boundary layer on 27 August. To get a large-scale view of aerosol optical thickness (AOT), we used aerosol retrievals from MODIS using the Multi-Angle Implementation of Atmospheric Correction (MAIAC) algorithm (Lyapustin et al., 2011, 2012a). MAIAC is a new algorithm which uses the time series analysis and processing of groups of pixels to detect clouds (Lyapustin et al., 2008) and derive surface bidirectional reflectance and aerosol properties. The AOT is provided at $1 \mathrm{~km}$ resolution in gridded format. In addition, MAIAC provides aerosol types as background, smoke and mineral dust, facilitated by the knowledge of the full spectral surface bidirectional reflectance distribution func-
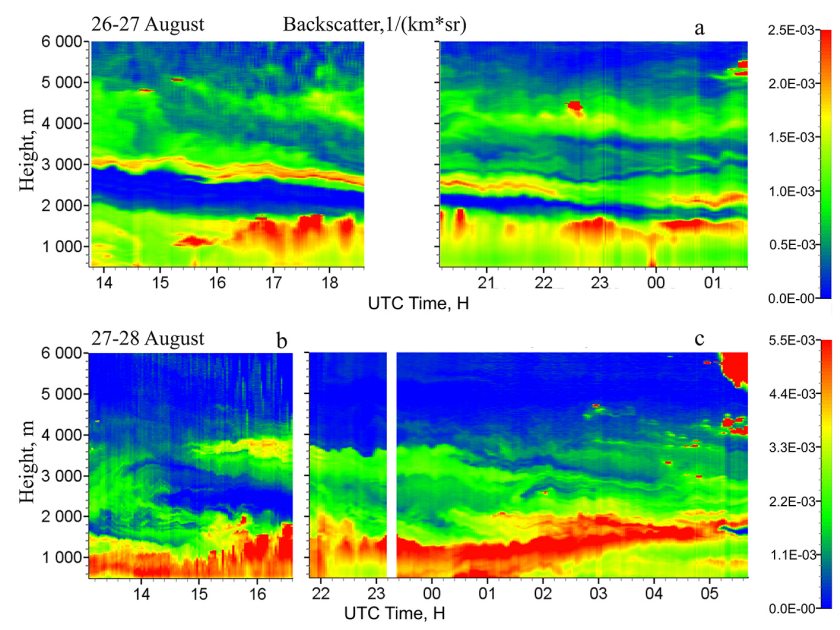

Figure 1. Backscattering coefficients at $355 \mathrm{~nm}$ calculated from Raman lidar measurements on 26-28 August 2013.

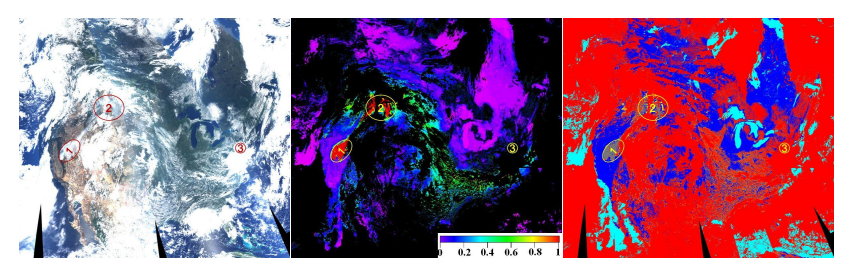

Figure 2. MODIS top-of-atmosphere RGB image (left), AOT at $470 \mathrm{~nm}$ retrieved from MODIS with the MAIAC algorithm (middle), and cloud mask (right). Cloud mask legend: red/yellow clouds; blue/light blue - clear over land/water; grey - smoke aerosol. The ovals point to Yosemite (1) and Idaho/Wyoming (2) fires, and the GSFC location (3).

tion (BRDF) for each $1 \mathrm{~km}$ grid cell. The smoke and dust separation is based on an enhanced shortwave absorption in the $0.412-0.67 \mu \mathrm{m}$ region (Lyapustin et al., 2012b), and on assessment of particle size. A continental-scale view of MAIAC AOT for 23 August 2013 is shown in Fig. 2 To cover North America, this figure combines several orbits from both Terra and Aqua. Shown are the MODIS top-of-atmosphere RGB image (left), along with MAIAC AOT $_{0.47}$ (middle) and cloud mask (right). The color scale of the cloud mask image indicates clouds (red, yellow), cloud shadows (dark red) and aerosol type for clear conditions. The blue/lightblue color represents background aerosol, and grey shows detected smoke. The presented image clearly shows two major fire regions across the entire area, in California (Yosemite National Park) and in Wyoming/Ohio, which agrees with the MODIS fire detection algorithm data set. A broader analysis of MAIAC retrievals for the second half of August shows that the mentioned two regions have been major sources of the biomass burning emissions. Clouds across the region show the west-east jet stream pattern which captures and transports lofted aerosols from the source regions. MAIAC aerosol type confidently captures smoke in the source regions 


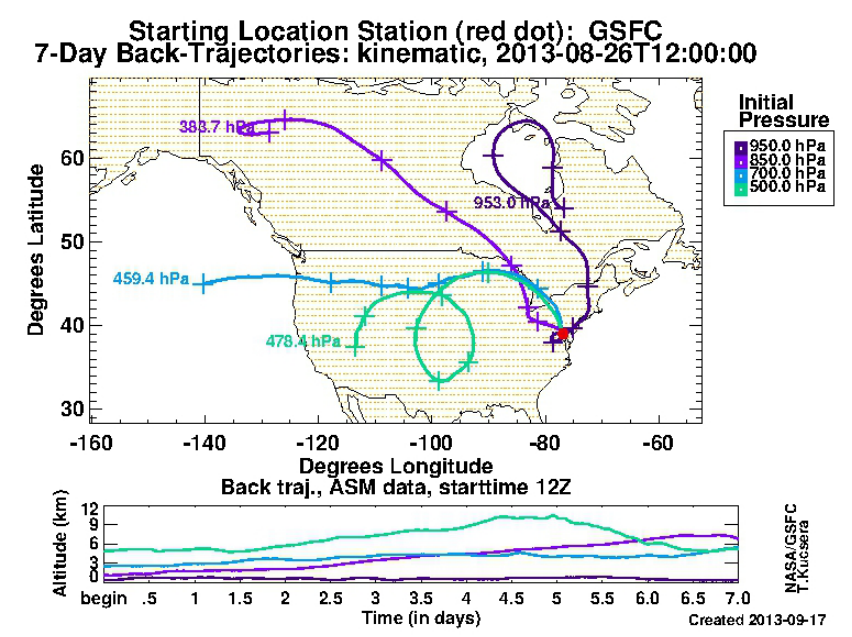

Figure 3. Back-trajectory analysis for 26 August 2013 at 12:00 UTC. An air parcel at the $700 \mathrm{hPa}$ level (an altitude corresponding to $\sim 3 \mathrm{~km}$ ) over GSFC came from the northwestern US fire region approximately 5 days earlier (as indicated by the blue line in the plot).

and also shows it in the Midwest and near the east coast, as shown by yellow ovals. These latter secondary aerosols are aged and modified; in addition to reduced AOT as compared to the source regions, they generally exhibit less absorption and are harder to detect, especially in highly cloudy environments.

To identify specific source of aerosols measured at GSFC, we have also conducted back-trajectory analysis, as shown in Fig. 3, and GOCART simulations of aerosol transport. The details of this and MAIAC-based analysis will be given in the coming companion paper. Below are two main results from this analysis:

1. The Raman lidar (RL) observations over GSFC during 26-28 August 2013 represent the long-range transport of biomass burning aerosol generated approximately 5 days earlier.

2. The enhanced free-tropospheric aerosol at $3-5 \mathrm{~km}$ altitude on 26 August comes from Wyoming/Idaho fires. This BB aerosol subsides and merges with local aerosol in the PBL on the next day, representing the bulk of pollution at the GSFC location. The aerosol produced by Californian fires appears right after the end of lidar operations on 28 August at relatively high altitude $(\sim 5-$ $7 \mathrm{~km}$ ). However, the end of lidar operational time was obscured by the cirrus clouds at and above this level.

Figure 4 shows aerosol backscattering at $355 \mathrm{~nm}$ similar to Fig. 1 but simulated by GEOS-5 GOCART. The simulated results confirm aerosol vertical layer structure and evolution revealed by the lidar profiles shown in Fig. 1, although the model's vertical resolution is much lower. The model sourcereceptor study further indicates that the observed distinct
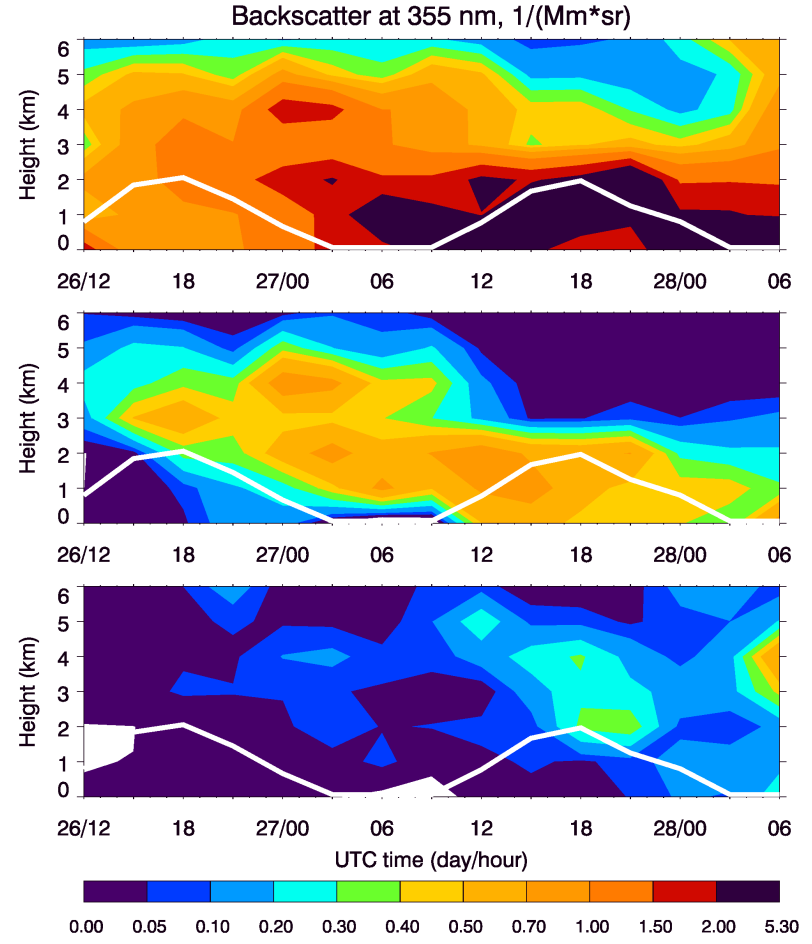

Figure 4. (a) Aerosol backscatter $\left((\mathrm{Mm} \mathrm{sr})^{-1}\right)$ at $355 \mathrm{~nm}$ simulated by the GEOS-5 GOCART model over GSFC from 00:00 UTC on 26 August to 06:00 UTC on 28 August 2013. (b and c) Similar to (a) but for biomass burning aerosol tagged to the Wyoming/Idaho (10$\left.118^{\circ} \mathrm{W}, 42-48^{\circ} \mathrm{N}\right)$ and Yosemite $\left(115-124^{\circ} \mathrm{W}, 36-42^{\circ} \mathrm{N}\right)$ fires, respectively. White lines represent planetary boundary height.

aerosol layer at $\sim 3 \mathrm{~km}$ altitude over GSFC during 26-27 August comes mainly from Wyoming/Idaho fires (Fig. 4b). The Yosemite source is mixed in, but at a much lesser degree during this period (Fig. 4c). The distinct Wyoming/Idaho aerosol layer subsides on 27 August and is mixed with local aerosols in the boundary layer, while the Yosemite source aerosol comes in aloft. The aerosol enhancement at $4-5 \mathrm{~km}$ altitude during the end of lidar measurement on August 28 (the last $1 \mathrm{~h}$ in Fig. 1) may be due to Yosemite smoke.

\subsection{Lidar-derived optical properties of smoke particles.}

26-27 August: on 26 August the strong smoke layers were present up to a height of $5000 \mathrm{~m}$, as is revealed by Fig. 1 . The gap between the PBL and the smoke layers, as for example at 14:00 UTC on 26 August, is clearly visible. The smoke layers descended with time, so the gap almost disappears by 01:00 UTC on 27 August. Examples of the vertical profile of backscattering coefficients $\left(\beta_{355}\right)$ from 26 August are shown in Fig. 5 for the periods 14:00-16:00, 16:30-18:30 and 20:30-22:30 UTC. The backscatter is observed to drop to 0 above the PBL and then to rise again. The strongest scattering by the smoke particles is represented by a relatively narrow peak which descends from $3 \mathrm{~km}$ height at 14:00 UTC 


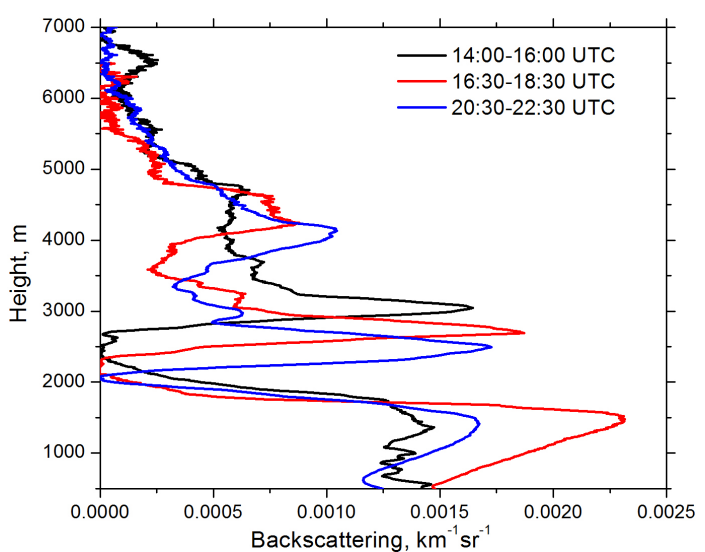

Figure 5. Vertical profiles of backscattering coefficients at $355 \mathrm{~nm}$ on 26 August averaged over time intervals: 14:00-16:00, 16:3018:30 and 20:30-22:30 UTC.

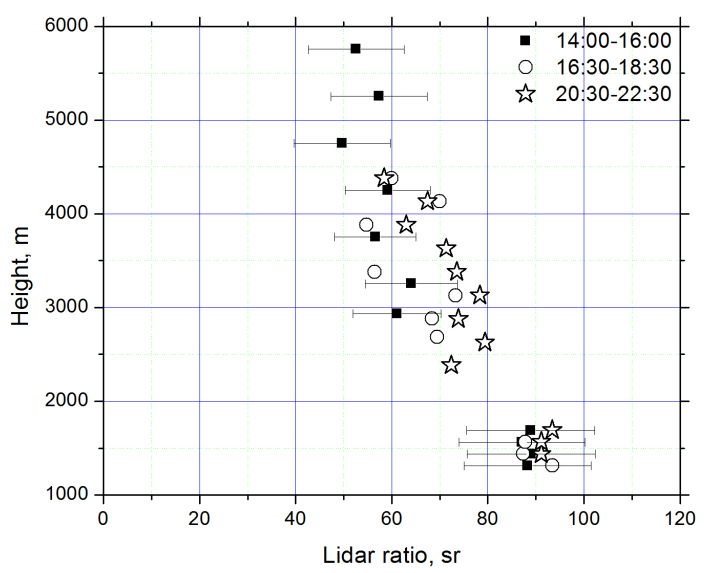

Figure 6. Lidar ratios at $355 \mathrm{~nm}$ on 26 August averaged over the same time intervals as in Fig. 5.

to $2.5 \mathrm{~km}$ at 22:00 UTC. Figure 6 shows the lidar ratios calculated at $355 \mathrm{~nm}\left(\mathrm{LR}_{355}\right)$ for the smoke particles over the same temporal interval as in Fig. 5. The backscattering and extinction coefficients have been vertically averaged with vertical resolution ranging from 100 to $250 \mathrm{~m}$. Inside the PBL the lidar ratios are approximately $90 \mathrm{sr}$, while in the region containing the smoke lidar ratios decrease. During the period of 14:00-16:00 UTC, the average value of $\mathrm{LR}_{355}$ above $3000 \mathrm{~m}$ is $57 \pm 12 \mathrm{sr}$. Later (20:30-22:30 UTC) it increases up to $68 \pm 15 \mathrm{sr}$ for the same heights. These lidar ratio values are consistent with results previously published, taking into account the relatively large range of reported values due to the differences in the origin of the smoke particles studied and their ages (e.g., Müller et al., 2007a, b; Amiridis et al., 2009; Murayama et al., 2004; Nicolae et al., 2013; Giannakaki et al., 2010).

27-28 August: the backscattering coefficient on $27 \mathrm{Au}-$ gust decreases rapidly for heights greater than $2000 \mathrm{~m}$, although some remnants of smoke can be observed up to a

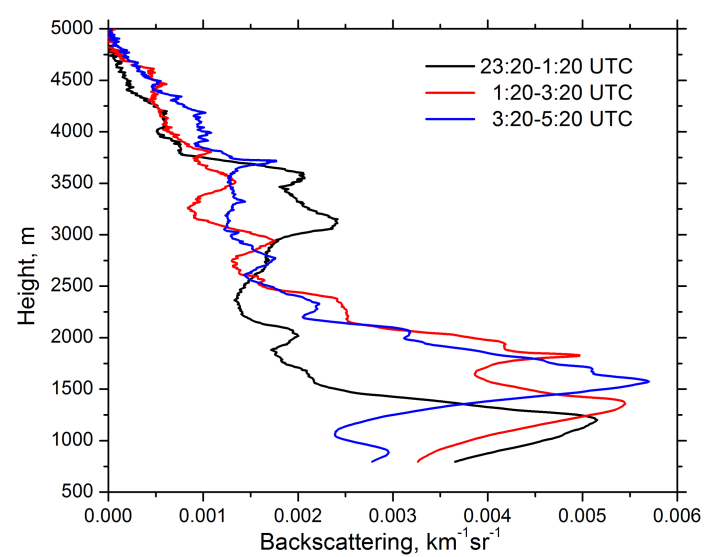

Figure 7. Vertical profiles of backscattering coefficients at $355 \mathrm{~nm}$ on 27-28 August averaged over 23:20-01:20, 01:20-03:20 and 03:20-05:20 UTC time intervals.

height of $5000 \mathrm{~m}$. Figure 7 shows vertical profiles of $\beta_{355}$ averaged over the periods of 23:20-01:20, 01:20-03:20 and 03:20-05:20 UTC. For the period of 23:20-01:20 UTC a significant enhancement of the backscattering is observed in the $3000-3750 \mathrm{~m}$ height interval, indicating the presence of an optically thick smoke layer. Beginning at 23:20 UTC, the extinction coefficients for both 355 and $532 \mathrm{~nm}$ were available, so the corresponding extinction Ångström exponent (EAE) $\gamma_{\alpha}$ and lidar ratios at both wavelengths could be calculated. The vertical profiles of lidar ratios are shown in Fig. 8 for the periods of 23:20-01:20 and 03:20-05:20 UTC. The lidar ratio $\mathrm{LR}_{355}$ is approximately $90 \mathrm{sr}$ below a height of $2000 \mathrm{~m}$, whereas in the smoke layer it decreases to $65-80 \mathrm{sr}$. In several publications on lidar measurements of smoke, the lidar ratio $\mathrm{LR}_{532}$ exceeded $\mathrm{LR}_{355}$ (Müller et al., 2007a; Murayama et al., 2004; Nicolae et al., 2013). In our study the ratio $\mathrm{LR}_{355} / \mathrm{LR}_{532}$ is mainly above 1 in the smoke-containing region (above $2000 \mathrm{~m}$ ) and $L_{532}$ exceeds $L_{3} R_{35}$ only in the 3000-3750 m layer for the 23:20-01.20 UTC period (Fig. 8a) when concentration of smoke particles was the highest.

Figure 9 shows EAE $\gamma_{\alpha}$ at $355-532 \mathrm{~nm}$ wavelengths calculated for the same temporal intervals as in Fig. 7. Inside the PBL the EAE rises with height from approximately 0.5 to 1.0 within the height range of 1000-2000 $\mathrm{m}$. The highest value $\gamma_{\alpha}=1.7$ is observed during the period of 23:20-01:20 UTC in the smoke layer at $2750 \mathrm{~m}$. Above that height $\gamma_{\alpha}$ decreases to $\gamma_{\alpha}=1.1$ at $3250 \mathrm{~m}$ (in the center of the aerosol layer in Fig. 7) and then starts rising again. For the other two temporal intervals EAE decreases with increasing height to $\gamma_{\alpha} \approx 1.0$ for altitudes above $4000 \mathrm{~m}$. The values of EAE observed in our measurements are in agreement with published results. For example, Müller et al. (2007b) reported typical value of $\gamma_{\alpha}$ for aged smoke to be $1.0 \pm 0.5$. Still we should keep in mind that values of $\gamma_{\alpha}$ measured at different locations may differ significantly, depending on smoke origin and aging 

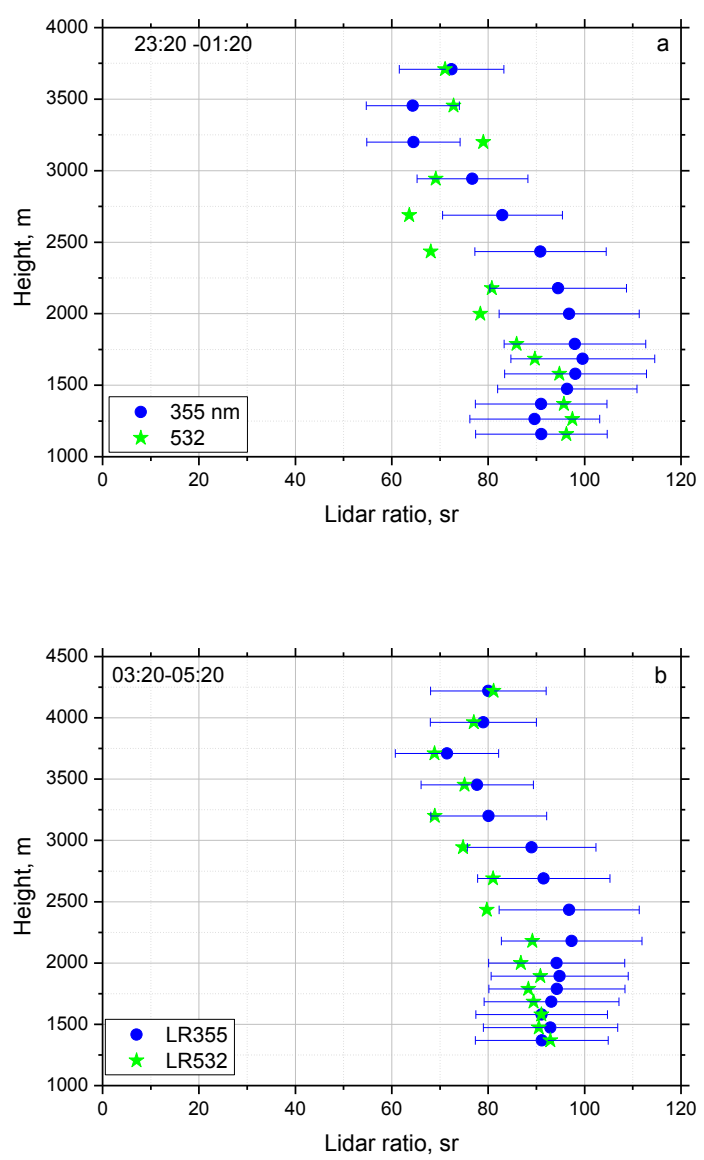

Figure 8. Lidar ratios at 532 and $355 \mathrm{~nm}$ for time interval (a) 23:20 01:20 and (b) 03:20-05:20 UTC on 27-28 August.

(Müller et al., 2005, 2007a, b; Murayama et al., 2004; Nicolae et al., 2013).

\subsection{Comparison with AERONET observations}

The results of lidar measurements were compared with observations of the collocated CIMEL sun photometer, which is a part of the AERONET network (Holben et al., 1998), in order to assess the contribution of the smoke layer to the total aerosol optical depth (AOD) measured by the sun photometer. The inversion algorithm making use of AODs at multiple wavelengths together with sky radiances permits the retrieval of columnar particle properties (Dubovik and King, 2000). Figure 10 shows a time series of columnar AOD at $340 \mathrm{~nm}$ and EAE $\gamma_{\alpha}$ for $340-500 \mathrm{~nm}$ wavelengths provided by AERONET on 26 and 27 August. The same figure shows the AOD of the smoke layer at $355 \mathrm{~nm}$ derived from Raman lidar measurements in the 2000-5000 m height range.

On 26 August sun photometer measurements after 18:20 UTC were removed by the cloud-screening algorithm (Smirnov et al., 2000). The EAE for the period 14:0018:00 UTC is approximately 1.6 and shows little variation. Extrapolating lidar-measured AOD to $340 \mathrm{~nm}$ via EAE, we

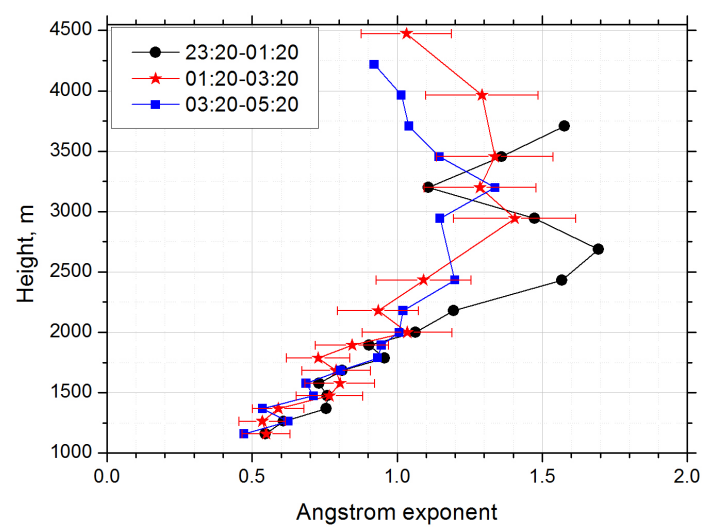

Figure 9. Ångström exponent for time intervals 23:20-01:20, 01:20-03:20 and 03:20-05:20 UTC on 27-28 August.

can conclude that contribution of the smoke layer to the total AOD for that period is about $35 \%$. On 27 August this contribution was even lower, and at 13:40 UTC it did not exceed $20 \%$. It is interesting that the AODs of the smoke layer on 26 and 27 August were similar, so the increase in AOD on 27 August is due to the boundary layer aerosol. The EAE on 27 August was about 1.2, and decrease in $\gamma_{\alpha}$ is likely due to the higher abundance of the PBL aerosols which have lower values of EAE than the smoke.

\section{Retrieval of particle microphysical properties from lidar measurements}

On 27 August the complete set of $3 \beta+2 \alpha$ data was available, so the particle microphysical properties - such as volume density $V$, effective radius $r_{\text {eff }}$ and complex refractive index - could be estimated. The example of such a data set for the time interval 03:20-05:20 UTC is presented in Fig. 11; the optical data are averaged over a height interval varying from 100 to $250 \mathrm{~m}$. Figure 12 shows the vertical profiles of $r_{\text {eff }}$ and $m_{\mathrm{R}}$ obtained for the same three temporal intervals as in Fig. 7 using the LE algorithm. The corresponding profiles of backscattering coefficients at $355 \mathrm{~nm}$ from Fig. 7 are also shown without scale in the figure for convenience of comparing the vertical variation of aerosol scattering. As mentioned in Sect. 2.1, the uncertainties of the retrieved values of $r_{\text {eff }}$ and $m_{\mathrm{R}}$ are estimated as $25 \%$ and \pm 0.05 , respectively, but relative changes in these quantities can be revealed with significantly lower uncertainty (Veselovskii et al., 2013). This permits the vertical variation of the particle parameters to be studied. During the first temporal interval, the effective radius decreases with height above $1500 \mathrm{~m}$ from 0.275 to $0.15 \mu \mathrm{m}$ at $2750 \mathrm{~m}$. In the center of the smoke layer at $3250 \mathrm{~m}$, however, the effective radius increases slightly up to $0.2 \mu \mathrm{m}$. The decrease of $r_{\mathrm{eff}}$ is accompanied by an increase of the real part of the CRI from $\sim 1.4$ at 1250 to $\sim 1.5$ at $3500 \mathrm{~m}$, which is a typical value for biomass 

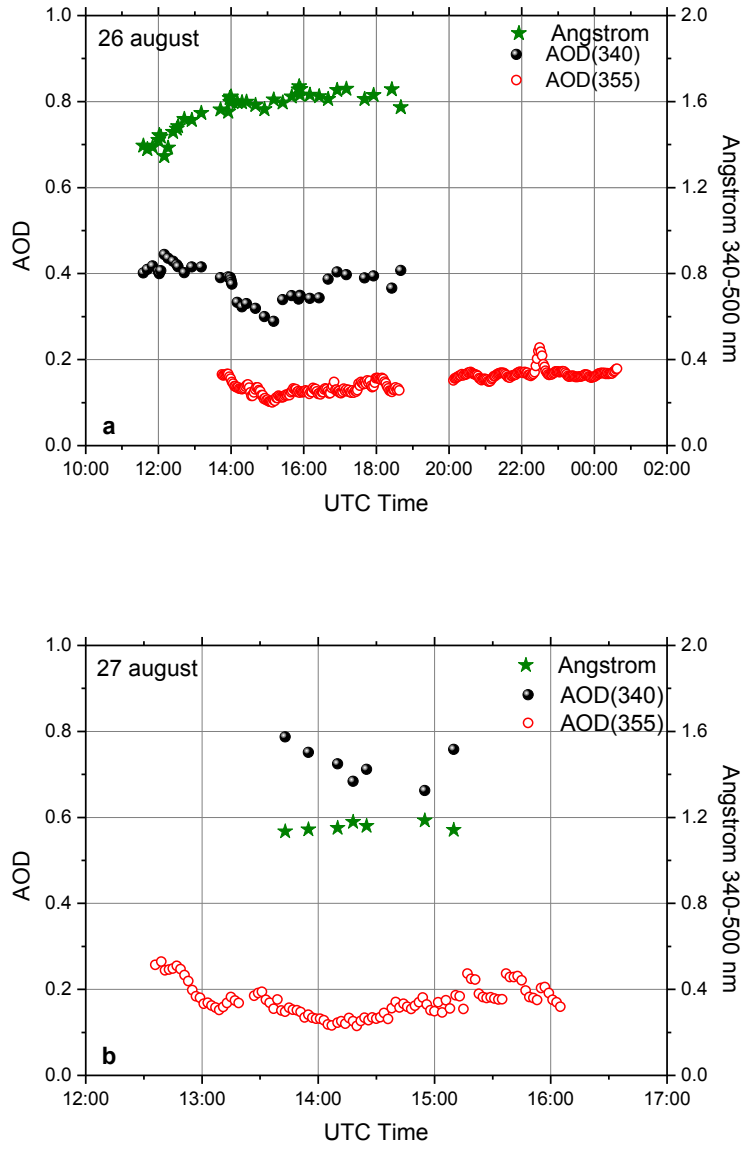

Figure 10. Aerosol optical depth at $340 \mathrm{~nm}$ and Ångström parameter at 340-500 nm provided by AERONET on (a) 26 and (b) 27 August 2013. Open symbols show optical depth of the smoke layer at $355 \mathrm{~nm}$ derived from Raman lidar measurements in the 2000 $5000 \mathrm{~m}$ height range.

burning aerosol (Dubovik et al., 2002). For the second and third temporal intervals the height variation of the effective radius is similar, but the minimum value of $r_{\text {eff }}$ in the smoke layer increases with a value during the third interval of approximately $0.2 \mu \mathrm{m}$. The enhancement of the real part of the CRI above $2000 \mathrm{~m}$ becomes smaller with time, and during the 03:20-05:20 UTC time interval a maximum value of $m_{\mathrm{R}}$ is approximately 1.43. Based on these results, we infer that during the interval of 23:20-01:20 UTC the smoke layer was the least influenced by external mixing, while for the other two temporal intervals partial mixing of the smoke with local aerosols may have occurred. The imaginary part of CRI in the smoke layer was estimated to be less than 0.0075 , but the high uncertainty of its retrieval in general does not permit evaluating the vertical distribution of $m_{\mathrm{I}}$.

On 27 August AERONET provides just a single Level 2.0 inversion at 13:44 UTC. The real part of the refractive index varies from 1.44 at $439 \mathrm{~nm}$ to 1.41 at $1020 \mathrm{~nm}$, while the imaginary part is below 0.004 for all wavelengths. These val-

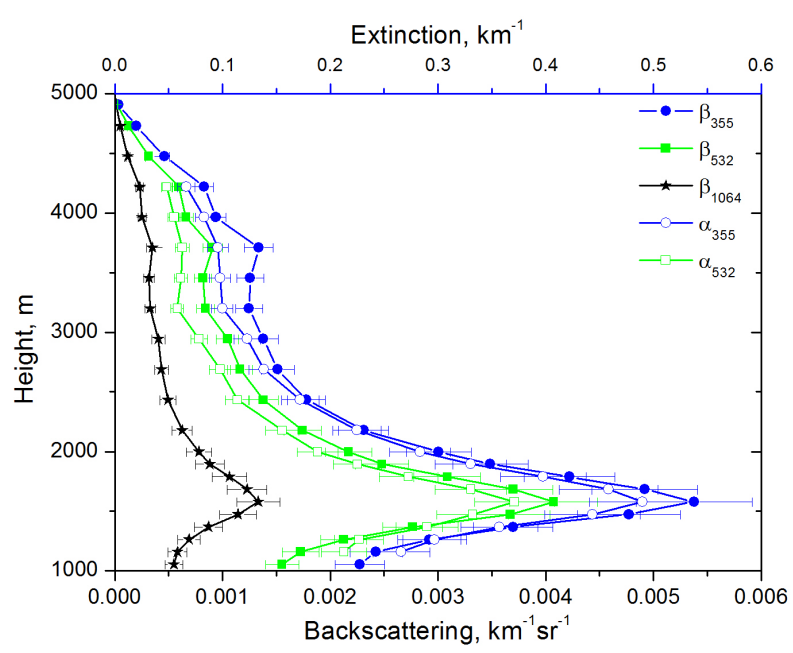

Figure 11. $3 \beta+2 \alpha$ optical data for time interval 03:20-05:20 UTC on 28 August.

ues are consistent with the lidar retrieval, given that the main contribution to the columnar properties was provided by the PBL particles. The effective radius provided by AERONET is $0.258 \mu \mathrm{m}$, which again is quite close to the lidar-retrieved values inside the PBL.

The vertical profiles of the particle volume density $V$ for these three temporal intervals are given in Fig. 13. The backscattering coefficient maximum shown in Fig. 4 moves upward with time, and the profiles of the volume density behave similarly. During the first temporal interval the maximum of $V$ is below $1000 \mathrm{~m}$, but during the third interval the maximum value of $V=50 \mu \mathrm{m}^{3} \mathrm{~cm}^{-3}$ is observed at $1500 \mathrm{~m}$ height. From Fig. 13 we conclude that most of the particle volume is contained inside the PBL and that the region associated with the smoke contributes much less to the columnar particle volume.

The regularization technique permits the main features of the particle size distribution (PSD) to be retrieved (Müller et al., 1999; Veselovskii et al., 2002). Figure 14 shows the volume distribution $\mathrm{d} V / \mathrm{d} \ln r$ obtained from the $3 \beta+2 \alpha$ lidar measurements during the interval of 01:20-03:20 UTC for the height layers centered at 1500, 2486 and $2816 \mathrm{~m}$. The width of the layers was $250 \mathrm{~m}$. In all three PSDs the fine mode dominates, which is typical for rural and biomass burning aerosols (Dubovik et al., 2002). Inside the PBL the maximum is achieved for $r \approx 0.3 \mu \mathrm{m}$, while at higher altitudes it shifts toward smaller radii reaching $r \approx 0.15 \mu \mathrm{m}$ at $2486 \mathrm{~m}$. However in the center of the smoke layer at $2816 \mathrm{~m}$, the maximum is again at approximately $r \approx 0.25 \mu \mathrm{m}$. The coarse mode is practically absent. As discussed in our earlier publication (Veselovskii et al., 2009), it may be due to the lower sensitivity of the lidar technique to big particles (maximal available wavelength is only $1064 \mathrm{~nm}$ ). For comparison Fig. 15 shows the PSDs provided by AERONET. On 26 August the contribution of the smoke layer to the colum- 

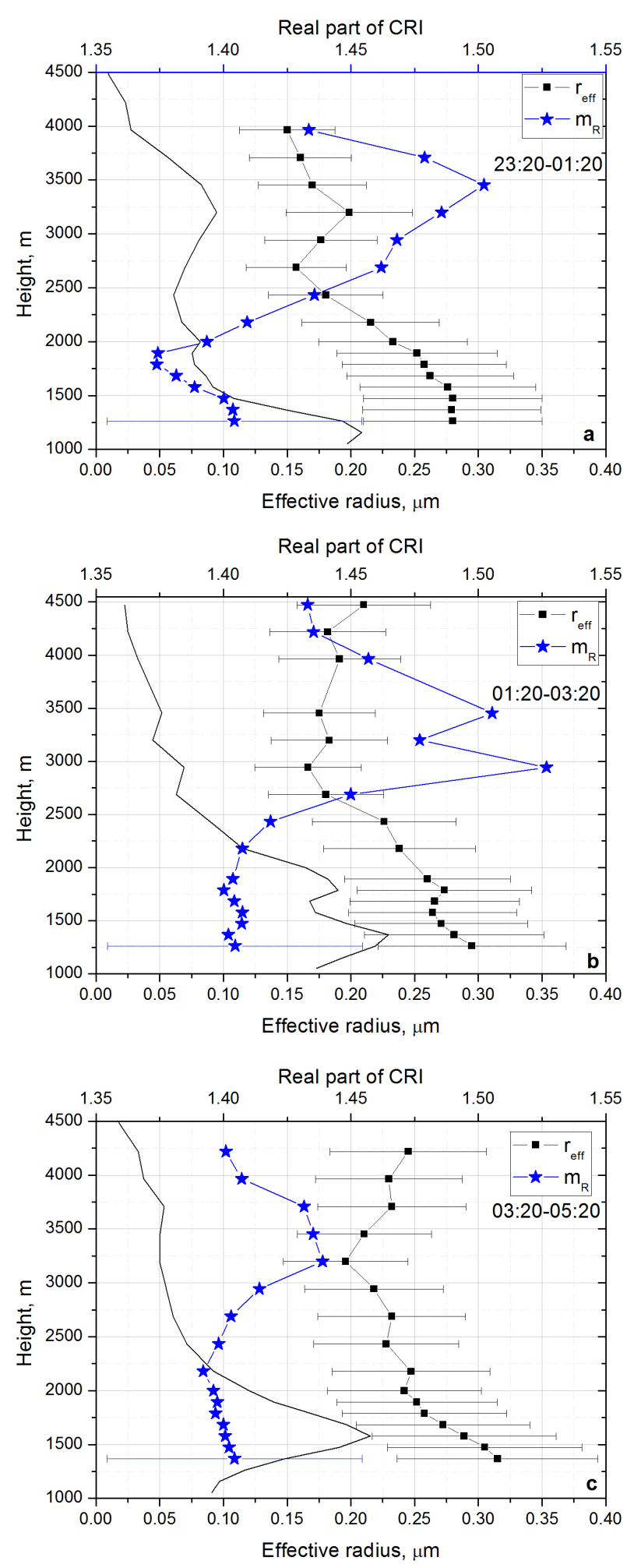

Figure 12. Effective radius (stars) and the real part of the refractive index (squares) derived from $3 \beta+2 \alpha$ measurements on 27-28 August for the same three time intervals as in Fig. 7. Solid lines show the profiles of backscattering coefficients at $355 \mathrm{~nm}$ without scale.

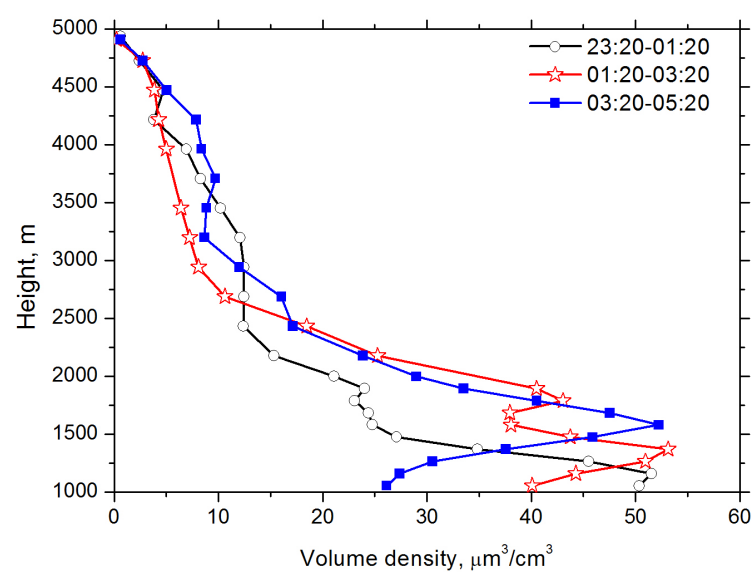

Figure 13. Vertical profiles of volume density on 27-28 August for the same time intervals as in Fig. 12.

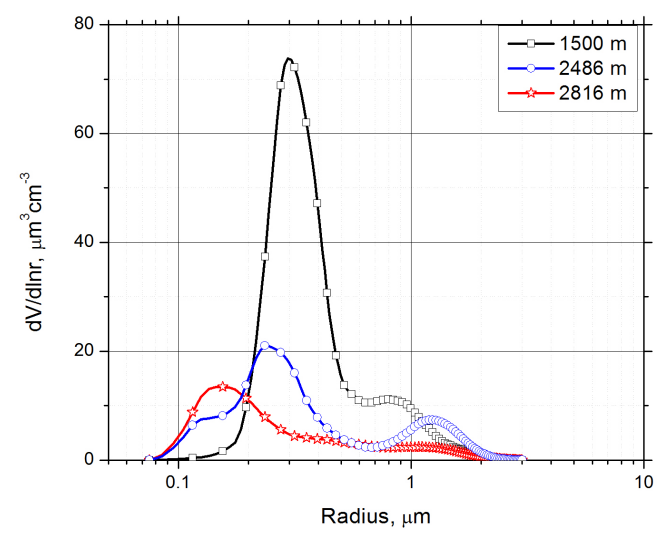

Figure 14. Particle size distributions for layers of $250 \mathrm{~m}$ centered at 1500,2486 and $2816 \mathrm{~m}$ derived from lidar measurements on 28 August during 01:20-03:20 UTC.

nar properties appears to have been more important, so the effective radius of the fine mode is rather small, about $0.15 \mu \mathrm{m}$ at 13:11 UTC. On 27 August the effective radius of the fine mode is larger (about $0.19 \mu \mathrm{m}$ ), because the main contribution to the columnar $r_{\text {eff }}$ is provided by the PBL particles. Thus at least for the fine mode the lidar and AERONET retrievals are in reasonable agreement.

As demonstrated previously, the linear estimation technique is fast and robust and permits large volumes of lidar measurements to be processed to provide time-height distributions of particle parameters (Veselovskii et al., 2012, 2013). Here we apply the same technique to study the evolution of the particle parameters on the night of 27 August. Figure 16 shows the particle extinction at $355 \mathrm{~nm}$ calculated by the Raman method. In this calculation the vertical resolution varied with height from $75 \mathrm{~m}$ (at $1000 \mathrm{~m}$ ) up to $200 \mathrm{~m}$ (at $6000 \mathrm{~m}$ ). The lidar signals were also smoothed in the temporal domain by using a sliding average of three profiles. The effective temporal resolution of the result was, therefore, ap- 


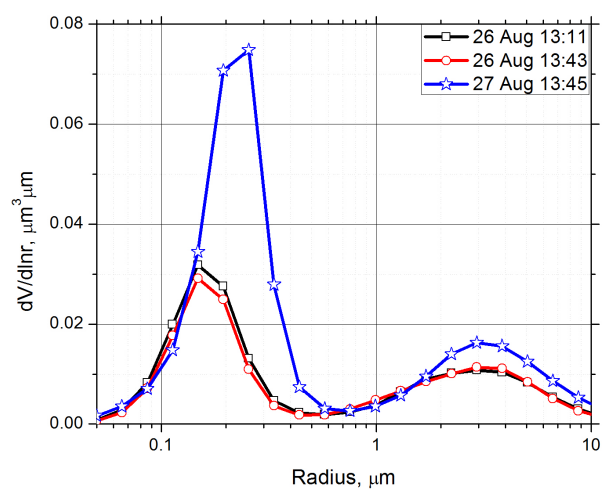

Figure 15. Column integrated particle size distributions provided by AERONET on 26 and 27 August.
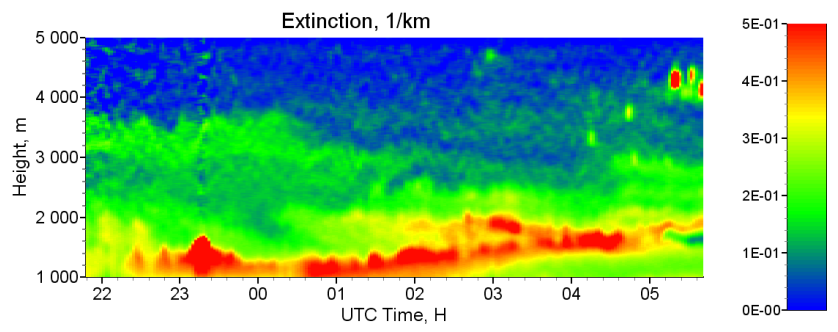

Figure 16. Aerosol extinction at $355 \mathrm{~nm}$ on $27-28$ August.

proximately $4 \mathrm{~min}$. Time-height distributions such as these were generated for all five input data to permit the particle parameters to be retrieved. The quality of the input data can be characterized by the discrepancy $\rho$, which is the difference between the measured input optical data and the optical data recalculated from the solution obtained using Mie kernels. The details of the $\rho$ calculation for the LE technique are given in Veselovskii et al. (2012). The time-height distribution of the discrepancy for the night of 27 August is shown in Fig. 17. Assuming that the uncertainties of the input data $\varepsilon_{\mathrm{i}}$ are independent, we can expect that for $\rho \sqrt{\varepsilon_{\mathrm{i}}^{2}}$ the retrieval becomes unreliable, which in our case $\left(\varepsilon_{\mathrm{i}} \sim 10 \%\right)$ corresponds to a value $\rho \sim 20 \%$, so we limit the inversion to heights below $4000 \mathrm{~m}$. We should mention also that the increase in $\rho$ in the 1000-1200 m layer toward the end of the measurement period could be partly explained by overlap function variation during long-term lidar operation.

The maps of volume density, effective radius and the real part of the refractive index retrieved from $3 \beta+2 \alpha$ measurements are shown in Fig. 18. The time-height distribution of volume concentration follows the corresponding distribution of the particle extinction, and we can observe upward movement with time of the layer with enhanced particle volume from $\sim 1000$ to almost $2000 \mathrm{~m}$ height. The effective radius is largest at low altitudes and then decreases above an altitude of approximately $2000 \mathrm{~m}$. During the night the region containing larger particles moves to higher altitudes. Above
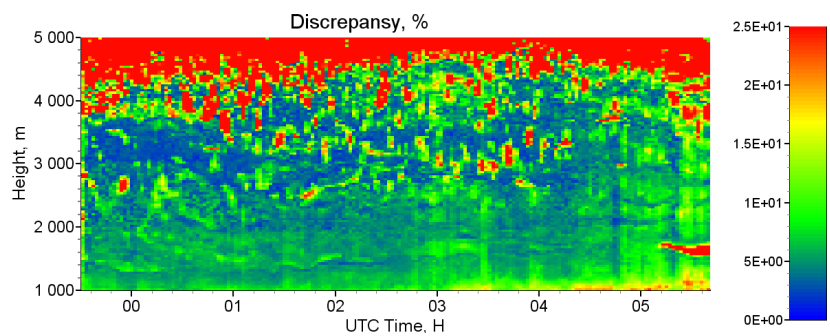

Figure 17. Discrepancy for the measurements on 27-28 August.
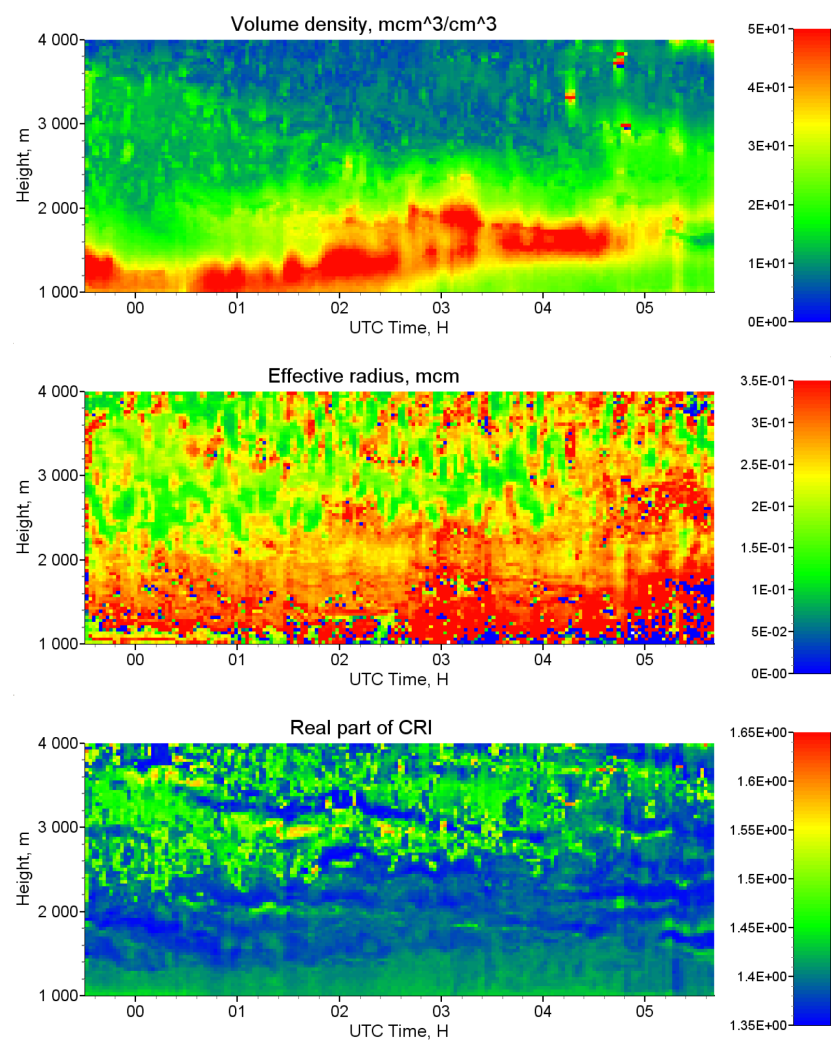

Figure 18. Height-time distribution of volume density, effective radius and the real part of the refractive index retrieved from $3 \beta+2 \alpha$ measurements on 27 August.

a height of $2000 \mathrm{~m}$, the real part of the refractive index is also enhanced, indicating the presence of smoke. The retrieval of effective radius is especially sensitive to the noise in $\alpha_{532}$ (Pérez-Ramírez et al., 2013), so oscillations in the calculated extinction at $532 \mathrm{~nm}$ are the main source of small-scale oscillation on the map for the effective radius. As shown previously, the exclusion of $\alpha_{532}$ from the input data removes this oscillation, thus making the maps smoother (Veselovskii et al., 2013). However, the reduced data set is less sensitive to the radius variation, especially for small particles, so some information about the vertical structure may be lost by using a reduced data set. Thus, improving the signal-to-noise quality of the $\alpha_{532}$ measurements is one of the priorities in 
upgrading the current version of the GSFC multi-wavelength Raman lidar.

\section{Analysis of backscatter-related Ångström exponent}

In numerous publications the backscatter-related Ångström exponent (BAE) $\gamma_{\beta}$ is considered to characterize the smoke particle properties, especially when $\gamma_{\alpha}$ is not available (Giannakaki et al., 2010; Amiridis et al., 2009). Tripled Nd:YAGbased lidar allows the calculation of the BAE for the wavelength intervals of 355-532 and 532-1064 nm (we will denote these as $\gamma_{\beta}(355-532)$ and $\gamma_{\beta}(532-1064)$ ), thus increasing the amount of available information. However, while the EAE does not depend significantly on the particle refractive index and thus characterizes mainly the particle size, the BAE depends on both particle size and refractive index. Thus relationships between $\gamma_{\alpha}$ and $\gamma_{\beta}$ are quite complicated (Su et al., 2008); to understand these relationships numerical simulation was performed. Extinction and backscatter Ångström exponents were calculated using Mie theory for a bimodal particle size distribution:

$$
\frac{\mathrm{d} n(r)}{\mathrm{d} \ln (r)}=\sum_{i=\mathrm{f}, \mathrm{c}} \frac{N_{\mathrm{i}}}{(2 \pi)^{1 / 2} \ln \sigma_{\mathrm{i}}} \exp \left[-\frac{\left(\ln r-\ln r_{i}\right)^{2}}{2\left(\ln \sigma_{\mathrm{i}}\right)^{2}}\right] .
$$

Here $N_{\mathrm{f}, \mathrm{c}}$ is particle number density in the fine (f) and the coarse (c) mode. Each mode is represented by a lognormal distribution with modal radius $r_{\mathrm{f}, \mathrm{c}}$ and dispersion $\ln \sigma_{\mathrm{f}, \mathrm{c}}$. In all simulations the value $\ln \sigma_{\mathrm{f}, \mathrm{c}}=0.4$ was used. The computation results are given in Fig. 19, showing $\gamma_{\beta}(355-532)$ and $\gamma_{\beta}(532-1064)$ vs. $\gamma_{\alpha}(355-532)$. In our study we considered both the effects of varying the modal radii and effects of varying the relative contribution of the fine mode to the PSD. The particle parameters used in the simulations were chosen to match typical properties of BB aerosols in order to aid interpretation of our observations. The results presented in Fig. 19 are obtained for the ratio of number density in the fine- and the coarse-mode $R_{\mathrm{N}}=\frac{N_{\mathrm{f}}}{N_{\mathrm{c}}}$ varying from $10^{2}$ to $10^{4}$, while the fine-mode radius varies in the range of $0.075-0.2 \mu \mathrm{m}$. The radius of the coarse mode is fixed at $r_{\mathrm{c}}=1.2 \mu \mathrm{m}$, and the particle refractive index is $m=1.45-i 0.005$. The contribution of the fine mode to the total volume for ratio $R_{\mathrm{N}}=10^{2}$ and $10^{4}$ is 16 and $95 \%$, respectively, for $r_{\mathrm{f}}=0.15 \mu \mathrm{m}$. In the first case the fine mode dominates in the PSD, while in the second case the main particle volume is contained in the coarse mode.

The solid lines in Fig. 19 show results for the fixed ratios $R_{\mathrm{N}}=10^{4}$ (upper curves) and $10^{2}$ (lower curves). At $R_{\mathrm{N}}=$ $10^{4}$ and considering the radius range $r_{\mathrm{f}}$ of $0.2-0.075 \mu \mathrm{m}, \gamma_{\alpha}$ ranges from 0 to 1.8 , while $\gamma_{\beta}$ for both wavelength pairs varies inside the interval of $0.8<\gamma_{\beta}<1.5$. Hence, for finemode predominance, the BAE is less sensitive to variation in the fine-mode radius than the EAE. The dashed lines illustrate the effect of varying the ratio of fine and coarse concentrations $R_{\mathrm{N}}$ for four chosen values of the fine-mode radius

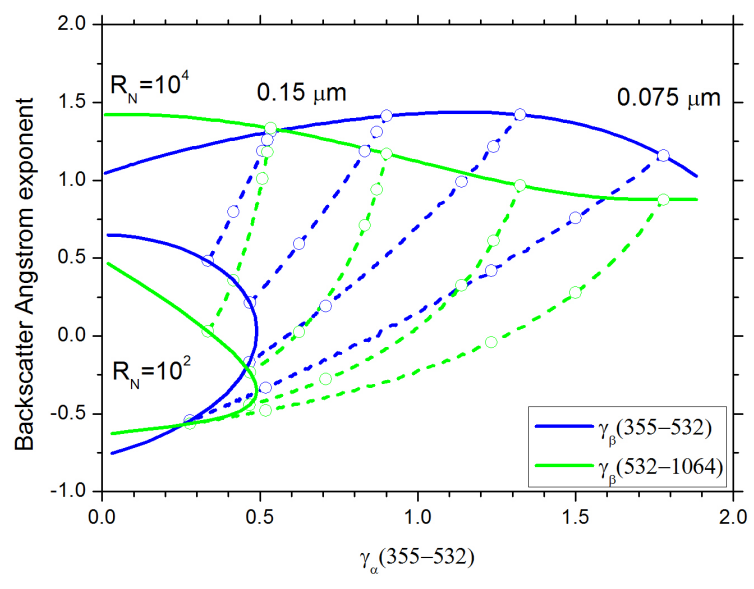

Figure 19. Backscatter Ångström exponents $\gamma_{\beta}(355-532)$ and $\gamma_{\beta}(532-1064)$ vs. $\gamma_{\alpha}(355-532)$. Solid lines show results for fixed ratios $R_{\mathrm{N}}=\frac{N_{\mathrm{f}}}{N_{\mathrm{c}}}=10^{2}, 10^{4}$, while $r_{\mathrm{f}}$ varies from 0.07 to $0.2 \mu \mathrm{m}$. Dash lines correspond to $R_{\mathrm{N}}$ varied in the range $10^{2}-10^{4}$ for chosen values $r_{\mathrm{f}}=0.075,0.1,0.125$ and $0.15 \mu \mathrm{m}$; open symbols mark results for $R_{\mathrm{N}}=10^{2}, 5 \times 10^{2}, 10^{3}, 5 \times 10^{3}$ and $10^{4}$. The complex refractive index used in computations is $\mathrm{m}=1.45-i 0.005$.

$r_{\mathrm{f}}=0.075,0.1,0.125$ and $0.15 \mu \mathrm{m}$. Increasing the coarsemode contribution leads to a rapid decrease of $\gamma_{\beta}$. As stated, these plots use a coarse-mode radius $r_{\mathrm{c}}=1.2 \mu \mathrm{m}$; however computations performed for $r_{\mathrm{c}}=1.0$ and $1.5 \mu \mathrm{m}$ lead to very similar results. Thus, the variation of the fine-mode radius $r_{\mathrm{f}}$ and the ratio $R_{\mathrm{N}}$ affects $\gamma_{\beta}$ and $\gamma_{\alpha}$ in different ways.

The plots in Fig. 19 were obtained for a fixed value of the refractive index. The backscatter Angström exponent is sensitive to variations in $m$, however, thus complicating interpretation of the results. The influence of the real part of CRI on $\gamma_{\beta}$ and $\gamma_{\alpha}$ dependence is illustrated by Fig. 20, showing plots for $m_{\mathrm{R}}=1.35,1.45$ and 1.55 . The imaginary part of CRI is $m_{\mathrm{I}}=0.005$ and ratio $R_{\mathrm{N}}=10^{4}$ for all plots. Just like in Fig. 19 the radius of the fine-mode $r_{\mathrm{f}}$ varies from 0.075 to $0.25 \mu \mathrm{m}$, while $r_{\mathrm{c}}=1.2 \mu \mathrm{m}$. From Fig. 20 we can also conclude that in the range $0.5<\gamma_{\alpha}<1.5$, which is typical for BB aerosols, $\gamma_{\beta}(355-532)$ is more sensitive to variations of $m_{\mathrm{R}}$ than $\gamma_{\beta}(532-1064)$. As was demonstrated by the retrievals in Fig. 12, the particles inside the PBL are characterized by low $m_{\mathrm{R}}$ and relatively high $r_{\text {eff }}$, while in the smoke layer the rise of the real part is accompanied by a decrease of the effective radius. To illustrate this evolution, in Fig. 20 the open stars mark two particle states. The first state with $r_{\mathrm{f}}=0.18 \mu \mathrm{m}\left(r_{\text {eff }}=0.325 \mu \mathrm{m}\right)$ and $m_{\mathrm{R}}=1.35$ corresponds to the PBL particle parameters, while the second state represents the smoke layer particles with $r_{\mathrm{f}}=0.085 \mu \mathrm{m}$ $\left(r_{\text {eff }}=0.185 \mu \mathrm{m}\right)$ and $m_{\mathrm{R}}=1.55$. Thus $\gamma_{\beta}$ and $\gamma_{\alpha}$ values calculated for the total vertical profile should provide the pattern corresponding to transition from "state 1" to "state 2".

To compare the simulation results with actual measurements, Fig. 21 shows vertical profiles of the backscatter 


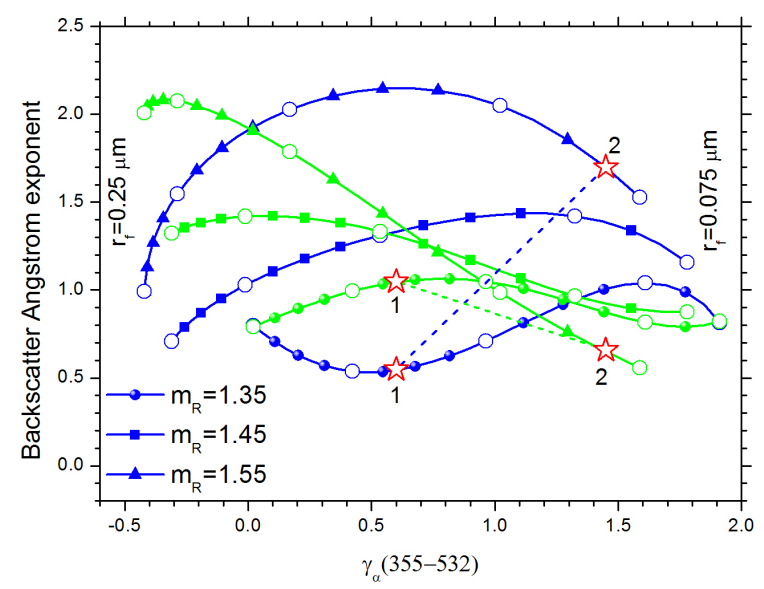

Figure 20. Backscatter Ångström exponents $\gamma_{\beta}$ (355-532) (blue) and $\gamma_{\beta}(532-1064)$ (green) vs. $\gamma_{\alpha}(355-532)$ for $R_{\mathrm{N}}=10^{4}$ and $r_{\mathrm{f}}$ varied in the range $0.075-0.25 \mu \mathrm{m}$. Results are given for $m_{\mathrm{R}}=1.35$, 1.45 and 1.55 ; the imaginary part is $m_{\mathrm{I}}=0.005$ for all curves. Open circles mark the points corresponding to $r_{\mathrm{f}}=0.075,0.1,0.15$, 0.2 and $0.25 \mu \mathrm{m}$. Dash lines show the "trajectories" when particle parameters change from $r_{\mathrm{f}}=0.18 \mu \mathrm{m}, m_{\mathrm{R}}=1.35$ (1, star) to $r_{\mathrm{f}}=0.085 \mu \mathrm{m}, m_{\mathrm{R}}=1.55(2, \mathrm{star})$.

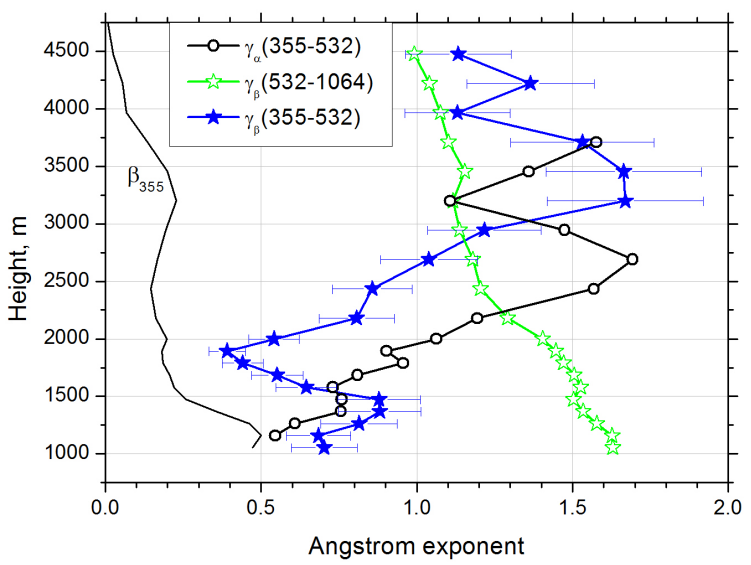

Figure 21. Vertical profiles of the backscatter Ångström exponents $\gamma_{\beta}(355-532)$ and $\gamma_{\beta}(532-1064)$ together with $\gamma_{\alpha}(355-532)$ measured on 27-28 August during 23:20-01:20 UTC. Solid lines show profile of backscattering coefficients at $355 \mathrm{~nm}$ without scale.

Ångström exponents $\gamma_{\beta}(355-532)$ and $\gamma_{\beta}(532-1064)$ together with $\gamma_{\alpha}(355-532)$ measured on 27-28 August during 23:20-01:20 UTC. The general trend of increasing $\gamma_{\alpha}$ with height is accompanied by the rise of $\gamma_{\beta}(355-532)$, while $\gamma_{\beta}(532-1064)$ decreases. A consideration of these results along with those in Fig. 12 indicates that the BAE $\gamma_{\beta}(355-$ 532 ) is highly sensitive to variations of $m_{\mathrm{R}}$. For example, an increase of the real part of CRI in the smoke layer up to a value of $m_{\mathrm{R}}=1.5$ (considering the retrievals in Fig. 8a) increases the value of $\gamma_{\beta}(355-532)$ to 1.7 at a height of $3250 \mathrm{~m}$, while $\gamma_{\alpha}$ decreases to 1.1 at this same height. It is interesting

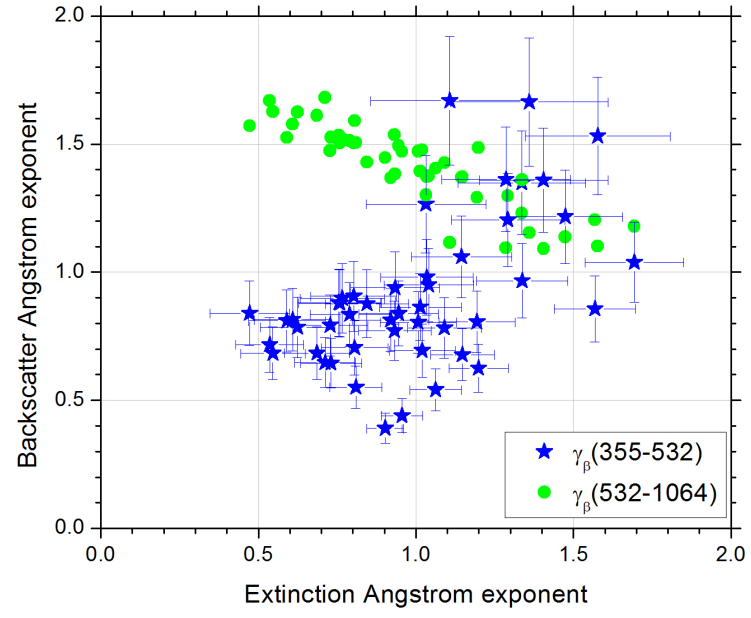

Figure 22. Backscatter Ångström exponents $\gamma_{\beta}(355-532)$ and $\gamma_{\beta}(532-1064)$ vs. $\gamma_{\alpha}(355-532)$ calculated from measurements on 27-28 August for the same three temporal intervals as in Fig. 7.

that the decrease of $\gamma_{\beta}(355-532)$ from 0.9 to 0.4 in the height layer 1500-2000 m matches the decrease of $m_{\mathrm{R}}$ in the same layer as shown in Fig. 12a. At the same time, $\gamma_{\beta}(532-1064)$ decreases gradually with height from 1.6 to 1.0 , indicating low sensitivity to the real part of CRI variation, which again agrees with the simulation results in Fig. 20.

The dependence of $\gamma_{\beta}(355-532)$ and $\gamma_{\beta}(532-1064)$ on $\gamma_{\alpha}(355-532)$ for 27-28 August is illustrated by Fig. 22, showing corresponding values for the same three time intervals as in Fig. 7. The patterns provided by $\gamma_{\beta}(355-532)$ and $\gamma_{\beta}(532-1064)$ are essentially different: $\gamma_{\beta}(355-532)$ in general increases with $\gamma_{\alpha}$, presenting strong data scattering due to high sensitivity to the refractive index; meanwhile $\gamma_{\beta}(532-1064)$ decreases with $\gamma_{\alpha}$ and data scattering is significantly lower. Such behavior is in agreement with patterns predicted by Fig. 20 (marked with stars).

Thus the results presented demonstrate that the backscatter Ångström exponents for the two wavelength pairs considered contain additional information about the height variation of aerosol size and refractive index. Such information can be used for preliminary analysis of lidar observations. For more complete information about the particle microphysical parameters, the full inversion of all $3 \beta+2 \alpha$ measurements should be performed as described in the previous sections.

\section{Summary and conclusions}

The multi-wavelength lidar technique was applied to the study of a forest fire smoke event observed near Washington, DC on 26-27 August 2013. Satellite observations combined with a transport model indicate that the smoke plume had its origin from Wyoming/Idaho forest fires and its transport to Washington, DC took about 5 days. This case was observed 
with the NASA GSFC multi-wavelength Mie-Raman lidar in order to accomplish two goals. The first goal was to get information about smoke particle intensive parameters such as lidar ratios and Ångström exponents at different wavelengths. The second goal was to test whether the multi-wavelength lidar technique is capable of resolving the height variation of particle microphysical parameters through the PBL and the region containing the smoke.

The intensive smoke particle parameters obtained are in agreement with findings of other authors, though when making such comparisons we should keep in mind that these parameters depend on many factors such as combustion phase, age and transport. As a result, the reported values present significant scattering. In our measurements, the lidar ratio at $355 \mathrm{~nm}$ in the unmixed smoke layer (on 26-27 August) was found to be $50 \pm 10 \mathrm{sr}$, and it was significantly higher than the value measured inside the PBL, where $\mathrm{LR}_{355}$ was found to be $90 \pm 10 \mathrm{sr}$. One of the specific features of smoke particles reported by several authors (Müller et al., 2007a, Nicolae et al., 2013) is that higher values of $\mathrm{LR}_{532}$ are obtained as compared to $\mathrm{LR}_{355}$. In our observations on 27 August the ratio of $\mathrm{LR}_{355} / \mathrm{LR}_{532}$ in the region containing the smoke was normally above 1 , and only in the strong smoke layer at $3000-3750 \mathrm{~m}$ height was the situation reversed. This may be an indication that, by the time of the observation, the smoke plume had been significantly diluted by local aerosols during transport.

The extinction and backscatter Ångström exponents are important parameters for particle characterization. The extinction Ångström exponent depends mainly on particle size, so interpretation of observations is quite straightforward. In our measurements on 27-28 August $\gamma_{\alpha}(355-532)$ increased with height from approximately 0.5 at $1000 \mathrm{~m}$ to $1.2-1.7$ in the smoke-containing region at $\sim 2800 \mathrm{~m}$, indicating that the smoke particles were rather small. The behavior of the backscatter Ångström exponents over the wavelength intervals of 355-532 and 532-1064 nm was quite different: $\gamma_{\beta}(355-532)$ grew strongly in the smoke layer, while $\gamma_{\beta}(532-1064)$ gradually decreased with height. Numerical simulations confirmed that, for the aerosol with dominating fine mode, the Ångström exponents $\gamma_{\beta}(355-532)$ and $\gamma_{\beta}(532-1064)$ have different dependence on the particle size and refractive index. The lidar-determined dependencies of $\gamma_{\beta}$ and $\gamma_{\alpha}$ were in agreement with the simulated results. The Ångström exponent $\gamma_{\beta}(355-532)$ is very sensitive to the refractive index, while $\gamma_{\beta}(532-1064)$ is less affected by variation of $m_{\mathrm{R}}$, so joint consideration of all Ångström exponents provides useful information for preliminary analysis of lidar observations. However, $\gamma_{\beta}$ is not unambiguously related to particle size, so it should be used with care; to get information about the particle size and refractive index, the full $3 \beta+2 \alpha$ data set should be inverted.

The inversion of lidar measurements on 27 August revealed that the particle effective radius decreased with height from approximately $0.27 \mu \mathrm{m}$ inside the PBL to $0.15 \mu \mathrm{m}$ in the elevated smoke layer. Simultaneously the real part of the CRI in the smoke layer increased to $m_{\mathrm{R}} \approx 1.5$. The retrievals demonstrate also that the fine mode is predominant in the particle size distribution, and that a decrease of the effective radius with height is due to the shift of the fine mode toward smaller radii. This fine-mode shift is consistent with AERONET column-integrated observations.

The results presented demonstrate that inversion of multiwavelength lidar measurements provides information about the height variation of particle volume, effective radius and the real part of CRI through the PBL and smoke layer. However, to perform such inversion with better spatial and temporal resolution, further improvement of the lidar system is needed. The main limitation is posed by the statistical uncertainties in the measurement of $\alpha_{532}$. The retrieval of effective radius is the most sensitive to the errors in extinction coefficients (Pérez-Ramírez et al., 2013), and the vibrational Raman backscatter at $608 \mathrm{~nm}$ is rather weak compared, for example, to that due to rotational Raman scattering at $532 \mathrm{~nm}$. Therefore, our upcoming plans are to augment the lidar instrument to measure rotational Raman scattering at $532 \mathrm{~nm}$ to supply the visible extinction coefficient needed for multiwavelength aerosol inversions.

Acknowledgements. Development of lidar retrieval algorithms was supported by Scientific Foundation of Russian Federation with grant 14-50-00034.

Edited by:M. Tesche

\section{References}

Adler, G., Flores, J. M., Abo Riziq, A., Borrmann, S., and Rudich, Y.: Chemical, physical, and optical evolution of biomass burning aerosols: a case study, Atmos. Chem. Phys., 11, 1491-1503, doi:10.5194/acp-11-1491-2011, 2011.

Amiridis, V., Balis, D. S., Giannakaki, E., Stohl, A., Kazadzis, S., Koukouli, M. E., and Zanis, P.: Optical characteristics of biomass burning aerosols over Southeastern Europe determined from UVRaman lidar measurements, Atmos. Chem. Phys., 9, 2431-2440, doi:10.5194/acp-9-2431-2009, 2009.

Ansmann, A. and Müller, D.: Lidar and atmospheric aerosol particles, in "Lidar. Range-Resolved Optical Remote Sensing of the Atmosphere", edited by: Weitkamp, C., 105-141, Springer, New York, 2005.

Ansmann, A., Riebesell, M., Wandinger, U., Weitkamp, C., Voss, E., Lahmann, W., and Michaelis, W.: Combined Raman elasticbackscatter lidar for vertical profiling of moisture, aerosols extinction, backscatter, and lidar ratio, Appl. Phys. B., 55, 18-28, 1992.

Ansmann, A., Baars, H., Tesche, M., Müller, D., Althausen, D., Engelmann, R., Pauliquevis, T., and Artaxo, P.: Dust and smoke transport from Africa to South America: Lidar profiling over Cape Verde and the Amazon rainforest, Geophys. Res. Lett., 36, L11802, doi:10.1029/2009GL037923, 2009. 
Baars, H., Ansmann, A., Althausen, D., Engelmann, R., Heese, B., Müller, D., Artaxo, P., Paixao, M., Pauliquevis, T., and Souza, R.: Aerosol profiling with lidar in the Amazon Basin during the wet and dry season, J. Geophys. Res., 117, D21201, doi:10.1029/2012JD018338, 2012.

Bian, H., Colarco, P. R., Chin, M., Chen, G., Rodriguez, J. M., Liang, Q., Blake, D., Chu, D. A., da Silva, A., Darmenov, A. S., Diskin, G., Fuelberg, H. E., Huey, G., Kondo, Y., Nielsen, J. E., Pan, X., and Wisthaler, A.: Source attributions of pollution to the Western Arctic during the NASA ARCTAS field campaign, Atmos. Chem. Phys., 13, 4707-4721, doi:10.5194/acp-13-47072013, 2013.

Böckmann, C., Miranova, I., Müller, D., Scheidenbach, L., and Nessler, R.: Microphysical aerosol parameters from multiwavelength lidar, J. Opt. Soc. Am. A., 22, 518-528, 2005.

Burton, S. P., Ferrare, R. A., Hostetler, C. A., Hair, J. W., Rogers, R. R., Obland, M. D., Butler, C. F., Cook, A. L., Harper, D. B., and Froyd, K. D.: Aerosol classification using airborne High Spectral Resolution Lidar measurements -methodology and examples, Atmos. Meas. Tech., 5, 73-98, doi:10.5194/amt-5-73-2012, 2012.

Chin, M., Ginoux, P., Kinne, S., Torres, O., Holben, B. N., Duncan, B. N., Martin, R. V., Logan, J. A., Higurashi, A., and Nakajima, T.: Tropospheric aerosol optical thickness from the GOCART model and comparisons with satellite and sun photometer measurements, J. Atmos., Sci., 59, 461-483, 2002.

Chin, M., Diehl, T., Tan, Q., Prospero, J. M., Kahn, R. A., Remer, L. A., Yu, H., Sayer, A. M., Bian, H., Geogdzhayev, I. V., Holben, B. N., Howell, S. G., Huebert, B. J., Hsu, N. C., Kim, D., Kucsera, T. L., Levy, R. C., Mishchenko, M. I., Pan, X., Quinn, P. K., Schuster, G. L., Streets, D. G., Strode, S. A., Torres, O., and Zhao, X.-P.: Multi-decadal aerosol variations from 1980 to 2009: a perspective from observations and a global model, Atmos. Chem. Phys., 14, 3657-3690, doi:10.5194/acp-14-3657-2014, 2014.

Colarco, P. R., Schoeberl, M. R., Doddridge, B. G., Marufu, L. T., Torres, O., and Welton, E. J.: Transport of smoke from Canadian forest fires to the surface near Washington, D. C.: Injection height, entrainment, and optical properties, J. Geophys. Res., 109, D06203, doi:10.1029/2003JD004248, 2004.

Colarco, P., da Silva, A., Chin, M., and Diehl, T.: On- line simulations of global aerosol distributions in the NASA GEOS-4 model and comparisons to satellite and groundbased aerosol optical depth, J. Geophys. Res., 115, D14207, doi:10.1029/2009JD012820, 2010.

De Graaf, M., Donovan, D., and Apituley, A.: Feasibility study of integral property retrieval for tropospheric aerosol from Raman lidar data using principal component analysis, Appl. Opt., 52, 2173-2186, 2013.

Dubovik, O. and King, M. D.: A flexible inversion algorithm for retrieval of aerosol optical properties from Sun and sky radiance measurements, J. Geophys. Res., 105, 20673-20696, 2000.

Dubovik, O., Holben, B. N., Eck, T. F., Smirnov, A., Kaufman, Y. J., King, M. D., Tanré, D., and Slutsker, I.: Variability of absorption and optical properties of key aerosol types observed in worldwide locations, J. Atmos. Sci., 59, 590-608, 2002.

Fiebig, M., Petzold, A., Wandinger, U., Wendisch, M., Kiemle, C., Stifter, A., Ebert, M., Rother, T., and Leiterer, U.: Optical closure for an aerosol column: Method, accuracy, and inferable properties applied to a biomass-burning aerosol and its radiative forc- ing, J. Geophys. Res., 107, 8130, doi:10.1029/2000jd000192, 2002.

Fiebig, M., Stohl, A., Wendisch, M., Eckhardt, S., and Petzold, A.: Dependence of solar radiative forcing of forest fire aerosol on ageing and state of mixture, Atmos. Chem. Phys., 3, 881-891, doi:10.5194/acp-3-881-2003, 2003.

Giannakaki, E., Balis, D. S., Amiridis, V., and Zerefos, C.: Optical properties of different aerosol types: seven years of combined Raman-elastic backscatter lidar measurements in Thessaloniki, Greece, Atmos. Meas. Tech., 3, 569-578, doi:10.5194/amt-3569-2010, 2010.

Hobbs, P. V., Reid, J. S., Kotchenruther, R. A., Ferek, R. J., and Weiss, R.: Direct radiative forcing by smoke from biomass burning, Science, 275, 1776-1778, 1997.

Holben, B. N., Eck, T. F., Slutsker, I., Tanre, D., Buis, J. P., Setzer, A., Vermote, E., Reagan, J. A., Kaufman, Y., Nakajima, T., Lavenu, F., Jankowiak, I., and Smirnov, A.: AERONET - a federated instrument network and data archive for aerosol characterization, Remote Sens. Environ., 66, 1-16,1998.

Lyapustin, A., Wang, Y., and Frey, R.: An Automatic Cloud Mask Algorithm Based on Time Series of MODIS Measurements, J. Geophys. Res., 113, D16207, doi:10.1029/2007JD009641, 2008.

Lyapustin, A., Wang, Y., Laszlo, I., Kahn, R., Korkin, S., Remer, L., Levy, R., and Reid, J. S.: Multi-Angle Implementation of Atmospheric Correction (MAIAC): Part 2. Aerosol Algorithm, J. Geophys. Res., 116, D03211, doi:10.1029/2010JD014986, 2011.

Lyapustin, A., Wang, Y., Laszlo, I., Hilker, T., Hall, F., Sellers, P., Tucker, J., and Korkin, S.: Multi-Angle Implementation of Atmospheric Correction for MODIS (MAIAC). 3: Atmospheric Correction, Remote Sens. Environ., 127, 385-393 doi:10.1016/j.rse.2012.09.002, 2012a.

Lyapustin, A., Korkin, S., Wang, Y., Quayle, B., and Laszlo, I.: Discrimination of biomass burning smoke and clouds in MAIAC algorithm, Atmos. Chem. Phys., 12, 9679-9686, doi:10.5194/acp12-9679-2012, 2012b.

Miller, D., Sun, K., Zondlo, M. A., Kanter, D., Dubovik, O., Welton, E. J., Winker, D. M., and Ginoux, P.: Assessing boreal forest fire smoke aerosol impacts on U.S. air quality: A case study using multiple data sets, J. Geophys. Res., 116, D22209, doi:10.1029/2011JD016170, 2011.

Müller, D., Wandinger, U., and Ansmann, A.: Microphysical particle parameters from extinction and backscatter lidar data by inversion with regularization: theory, Appl. Opt. 38, 2346-2357, 1999.

Müller, D., Mattis, I., Wandinger, U., Ansmann, A., Althausen, D., and Stohl, A.: Raman lidar observations of aged Siberian and Canadian forest fire smoke in the free troposphere over Germany in 2003: Microphysical particle characterization, J. Geophys. Res., 110, D17201, doi:10.1029/2004JD005756, 2005.

Müller, D., Mattis, I., Ansmann, A., Wandinger, U., Ritter, C., and Kaiser, D.: Multi-wavelength Raman lidar observations of particle growth during long-range transport of forest-fire smoke in the free troposphere, Geophys. Res. Lett., 34, L05803, doi:10.1029/2006gl027936, 2007a.

Müller, D., Ansmann, A., Mattis, I., Tesche, M., Wandinger, U., Althausen, D., and Pisani, G.: Aerosol-type-dependent lidar ratios observed with Raman lidar, J. Geophys. Res.-Atmos., 112, D16202, doi:10.1029/2006jd008292, 2007b. 
Murayama, T., Muller, D., Wada, K., Shimizu, A., Sekiguchi, M., and Tsukamoto, T.: Characterization of Asian dust and Siberian smoke with multi-wavelength Raman lidar over Tokyo, Japan in spring 2003, Geophys. Res. Lett., 31, L23103, doi:10.1029/2004g1021105, 2004.

Nicolae, D., Nemuc, A., Müller, D., Talianu, C., Vasilescu, J., Belegante, L., and Kolgotin, A.: Characterization of fresh and aged biomass burning events using multi-wavelength Raman lidar and mass spectrometry, J. Geophys. Res., 118, 2956-2965, doi:10.1002/jgrd.50324, 2013.

O’Neill, N. T., Eck, T. F., Holben, B. N., Smirnov, A., Royer, A., and Li, Z.: Optical properties of boreal forest fire smoke derived from Sun photometry, J. Geophys. Res., 107, 4125, doi:10.1029/2001JD000877, 2002.

Pérez-Ramírez, D., Aceituno, J., Ruiz, B., Olmo, F. J., and AladosArboledas, L.: Development and calibration of a star photometer to measure the aerosol optical depth: Smoke observations at a high mountain site, Atmos. Environ., 42, 2733-2738, 2008.

Pérez-Ramírez, D., Whiteman, D. N., Veselovskii, I., Kolgotin, A., Korenskiy, M., and Alados-Arboledas, L.: Effects of systematic and random errors on the retrieval of particle microphysical properties from multiwavelength lidar measurements using inversion with regularization, Atmos. Meas. Tech., 6, 3039-3054, doi:10.5194/amt-6-3039-2013, 2013.

Pratt, K. A., Murphy, S. M., Subramanian, R., DeMott, P. J., Kok, G. L., Campos, T., Rogers, D. C., Prenni, A. J., Heymsfield, A. J., Seinfeld, J. H., and Prather, K. A.: Flight-based chemical characterization of biomass burning aerosols within two prescribed burn smoke plumes, Atmos. Chem. Phys., 11, 1254912565, doi:10.5194/acp-11-12549-2011, 2011.

Reid, J. S., Koppmann, R., Eck, T. F., and Eleuterio, D. P.: A review of biomass burning emissions part II: intensive physical properties of biomass burning particles, Atmos. Chem. Phys., 5, 799825, doi:10.5194/acp-5-799-2005, 2005a.
Reid, J. S., Eck, T. F., Christopher, S. A., Koppmann, R., Dubovik, O., Eleuterio, D. P., Holben, B. N., Reid, E. A., and Zhang, J.: A review of biomass burning emissions part III: intensive optical properties of biomass burning particles, Atmos. Chem. Phys., 5, 827-849, doi:10.5194/acp-5-827-2005, 2005 b.

Smirnov A., Holben, B. N., Eck, T. F., Dubovik, O., and Slutsker, I.: Cloud screening and quality control algorithms for AERONET database, Remote Sens. Environ., 73, 337-349, 2000.

Su, W., Schuster, G. L., Loeb, N. G., Rogers, R. R., Ferrare, R. A., Hostetler, C. A., Hair, J. W., and Obland, M. D.: Aerosol and cloud interaction observed from high spectral resolution lidar data, J. Geophys. Res., 113, D24202, doi:10.1029/2008JD010588, 2008.

Tesche, M., Ansmann, A., Müller, D., Althausen, D., Engelmann, R., Freudenthaler, V., and Groß, S.: Vertically resolved separation of dust and smoke over Cape Verde by using multi-wavelength Raman and polarization lidar during SAMUM 2008, J. Geophys. Res., 114, D13202, doi:10.1029/2009JD011862, 2009.

Veselovskii I., Kolgotin, A., Griaznov, V., Müller, D., Wandinger, U., and Whiteman, D.: Inversion with regularization for the retrieval of tropospheric aerosol parameters from multi-wavelength lidar sounding, Appl. Opt., 41, 3685-3699, 2002.

Veselovskii I., Whiteman, D. N., Kolgotin, A., Andrews, E., and Korenskii, M.: Demonstration of aerosol property profiling by multi-wavelength lidar under varying relative humidity conditions, J. Atmos. Ocean. Tech., 26, 1543-1557, 2009.

Veselovskii, I., Dubovik, O., Kolgotin, A., Korenskiy, M., Whiteman, D. N., Allakhverdiev, K., and Huseyinoglu, F.: Linear estimation of particle bulk parameters from multi-wavelength lidar measurements, Atmos. Meas. Tech., 5, 1135-1145, doi:10.5194/amt-5-1135-2012, 2012.

Veselovskii, I., Whiteman, D. N., Korenskiy, M., Kolgotin, A., Dubovik, O., Perez-Ramirez, D., and Suvorina, A.: Retrieval of spatio-temporal distributions of particle parameters from multiwavelength lidar measurements using the linear estimation technique and comparison with AERONET, Atmos. Meas. Tech., 6, 2671-2682, doi:10.5194/amt-6-2671-2013, 2013. 